\title{
Dynamique de la polycentralité urbaine au Saguenay et les jeunes face à la culture de la communication
}

\author{
Pierre-W. Boudreault et Martin Sasseville \\ Université du Québec à Chicoutimi
}

Apparemment, tout ce qui donne à la vie quelque intérêt est dangereux pour l'ordre établi. ${ }^{1}$

Si l'on dit des Québécois que c'est de façon urbaine qu'ils habitent la campagne, la culture est donc un excellent moyen de comprendre ce qui relie les habitants de la campagne et les résidents des milieux urbains. Le cadre urbain-rural d'une région éloignée participe de manière fondamentale à la compréhension de l'organisation ou à la désorganisation culturelle qui relie tous les citoyens d'un même espace économique et du même environnement politique. D'autant plus que, dans la période actuelle de transition de la société postindustrielle à la société des communications, il est devenu urgent de s'interroger sur la place stratégique qu'occupe la culture dans le monde contemporain, d'observer son impact sur la transformation de notre cadre de vie, notre espace habité, et de voir comment la culture constitue la matière première d'un essor économique dans un monde globalisé. Pour ce faire, une petite définition de la culture sera nécessaire afin de pouvoir, par la suite, mesurer ses conséquences sur la recomposition de l'espace et pour être en mesure d'effectuer les choix stratégiques qui s'imposent, notamment auprès de la jeune génération actuelle.

Une nouvelle culture est déjà bien en place et son influence sur les modes de vie est bien palpable dans les pratiques quotidiennes de l'espace habité au Saguenay. De métropole conçue en un système composé de villes et de villages qui détermine une dynamique régionale-nationale, on est passé à une autre dynamique culturelle où une «métapole » ${ }^{2}$ tournée, cette fois sur le mondial, intègre la diversité culturelle et la complexité sociale comme "ressources naturelles » et comme « matières premières ». Les villes et les campagnes constituent ensemble une « dynamique globale plus forte que la somme de ses composantes », et cette dynamique façonne un espace complexe de communication où se manifeste la personnalité de tout un chacun et ce, dans une présence réelle à l'autre devenue possible dans la mesure où la distance sociale est assurée. Ce texte propose une réflexion au sujet d'un concept culturel de l'espace habité; ainsi, le concept de métapole signale une dynamique à la fois d'équilibre et de tension entre l'urbain et le rural, entre les espaces plus densément peuplés et les zones faiblement occupées, entre les différentes catégories sociales et les divers modes de vie. La métapolisation de l'espace s'accommode davantage de la diversité que de l'identité, et la culture de la différence prospère plus facilement dans des milieux familiarisés à l'idée de la complexité sociale qu'à l'idée de répétition-« mêmeté » ici (copier-répliquer) ce qui se fait ailleurs. Comme le définit Guy Rocher, la culture contribue à la construction de «l'univers mental, moral et symbolique, commun à une pluralité de persones, grâce auquel et à travers lequel ces personnes peuvent communiquer entre elles, se reconnaissent des liens, des attaches, des intérêts communs, des divergences et des oppositions, se sentent enfin, chacune individuellement et toutes collectivement, membres d'une même entité qui les dépasse et qu'on appelle un groupe, une association, une collectivité, une société ${ }^{3}$. Et, une société ne peut pas se définir sans penser le rapport qu'elle entretient à son espace. 


\section{La culture urbaine et les citoyens : une implication}

On peut vérifier le sens de cette définition à partir de l'analyse et de l'interprétation des informations recueillies lors d'une enquête d'opinion réalisée à l'été 2003 sur un échantillon de résidents et d'acteurs socio-économiques prélevé au centre-ville d'un des pôles urbains du Saguenay. Les répondants ont clairement signalé ce que la culture avait d'attractif. La population d'enquête a, par exemple, identifié le festival de jazz de Montréal, le festival d'été de Québec, le festival western de Saint-Tite, etc. comme étant leurs préférences dans leurs décisions de vacances. On voit donc que la culture prend le sens d'une mise en relation sociale, ou plus précisément une communication avec les autres, et du plaisir à se retrouver parmi une variété de gens venus de partout pour constituer un rassemblement festif où toutes les combinaisons de rencontres sont possibles.

Contre toute attente, les répondants n'ont pas exprimé le désir d'être spectateurs passifs ni qu'on leur donne simplement «accès à la culture ou aux équipements culturels ». Ils n'ont pas davantage souhaité être ceux à qui on enseignerait à apprécier le patrimoine «culturel », tout au moins à qui on « donnerait le goût de fréquenter la culture » afin de « développer une identité culturelle commune dans la préservation de notre diversité ${ }^{4}$. Il faut bien convenir que les répondants ont exprimé ce que la culture signifie de communications et de rapprochements dynamiques dans le monde contemporain. On ne veut pas être réduit à un rôle passif de consommateur assis dans des estrades ou d'autres se manifesteraient, mais on a plutôt signifié qu'on voulait être celui qui est mis immédiatement en cause comme acteur dans un rapport d' $\mathrm{d}^{\text {impli- }}$ cation », comme l'écrit Fernand Dumont ${ }^{5}$, dans une culture en acte. Bref, on veut participer à l'action, c'est-à-dire être présent au moment où s'expriment les désirs d'émerveillement et les sentiments d'évasion, faire corps avec l'animation urbaine, construire ce qui fait culture. Cet état d'esprit est souligné par leur satisfaction à déambuler en paix dans les centresvilles où sévissent des grands rassemblements festifs et sportifs. Cela exprime un désir de grégarité, et la culture est donc synonyme, pour les répondants, au fait de pouvoir se rapprocher des autres, de disposer de cadres tels qu'on puisse agréablement se perdre dans la foule, être en absence de contraintes (ou en

adhésion), mais dans un cadre esthétique édificateur, bref de vivre un ré enchantement dans le collectif.

\section{Contre toute attente, les répondants n'ont pas exprimé le désir d'être spectateurs passifs ni qu'on leur donne simplement « accès à la culture ou aux équipements culturels ».}

\section{Dans la société de communication, on change de citadinité}

Si la ville est le théâtre par lequel l'individu éprouve son existence sociale, celle-ci est complexe et diversifiée dans la société contemporaine où, écrit W. Dressler, " on change de citadinité " ${ }^{6}$. L'émergence d'une société nouvelle façonne un tissu urbain nouveau, et une économie fondée sur la communication et l'information repose sur un mode de vie qui suscite un support spatial nouveau. À titre d'indication, la mobilité spatiale des travailleurs ne se limite plus, et ce depuis un bon moment, aux déplacements à l'intérieur des murs de la cité. La mobilité est infranationale et internationale. Si l'on décode le sens des conclusions des recherches sur les explications de la mobilité des jeunes des régions éloignées, les attraits pour les grandes villes d'accueil sont ainsi désignés : possibilités d'ouverture aux expériences nouvelles; capacités de « rapprochements » tant professionnels que sociaux; occasions multiples qui favorisent diverses manifestations d'autonomie. Bref, les déplacements motivés pour des raisons strictement instrumentales et d'ordre financier, tels les mouvements pendulaires du matin et du soir entre la résidence et l'usine/bureau, n'épuisent plus la palette des explications à la mobilité. Les télécommunications ont ouvert des horizons et créé des domaines d'activités qu'on doit détecter par les indices révélateurs d'une société et de son urbanité nouvelle.

Si une communauté traditionnelle pouvait se satisfaire d'une vision muséologique de son patrimoine et se retrancher dans son passé socio-historique, la société contemporaine ne peut pas se concevoir comme étant immobilisée en évitant toute mobilité des individus, sans risquer de compromettre ce qui veut vivre comme transmission et création des valeurs. Les voies de circulation dans une ville sont des empreintes qui révèlent le choix donné à la culture par les citadins 
d'hier et d'aujourd'hui. À telle enseigne qu'il suffit souvent de se rendre compte des tracés et des moyens de communication dans une ville pour connaître l'état culturel d'une société. Les voies de communication signalent assez précisément les axes et les lieux privilégiés à partir desquels une société a situé ses valeurs. L'économie d'après-guerre puis la modernisation industrielle effectuée à l'issue de la Révolution tranquille ont tracé sur le territoire de la région des lignes directrices de ce qui constitue sa culture moderne axée sur les industries des pâtes et papiers et de l'aluminium. Il faut donc emprunter des voies de travers, des diagonales pour accéder à l'ensemble du patrimoine, au risque de voir se transformer la vie sociale en un parcours sillonné par la routine et les habitudes de gens vivant en silo, engoncés dans des sincérités identitaires opaques de travailleurs ou de cadres subissant leur itinéraire quotidien au milieu d'une ville-musée hostile à l'existence.

\section{La culture et la communication, une « communauté de destin »}

Si les gens désirent l'implication dans un bain culturel varié, il faut aussi avancer et poser la question fondamentale. La culture est la force fondamentale de mise en relation entre les individus. Elle forme la société en agissant en tant que catalyseur de la solitude des individus de plus en plus libérés en les reliant et en les rassemblant. Michel Maffesoli donne un sens particulièrement fort en le qualifiant de «terreau dans lequel prend racine la vie sociale $»^{7}$. La culture atteste l'existence du lien qui fait la vie en société, et ce faisant l'oppose à la violence.

Ainsi, la culture est inhérente à la vie citoyenne qui fait la société. Cependant, il faut être en mesure de se dire (langage) dans la ville pour ensuite savoir faire (fabriquer) avec les autres dans une dynamique d'action par consensus, sans d'abord fixer les finalités d'actions, et cela nécessite des cadres spatio-temporels communs. La question de la présence aux autres oblige la redéfinition de la confiance à ceux qui sont proches de soi. Une proximité et un voisinage qui définissent une communauté de destin, ou un « état d'esprit » réciproque, est alors vouée à façonner une dynamique spécifique qu'il convient de convertir en force originale et en mode de vie désirable. Un lieu vécu avec les autres érige une identité particulière fondée sur une constellation de références puisée à la source des expériences partagées. Voilà ce qui donne sens à l'espace géo-politico-économique commun et qui façonnera le récit puis l'histoire sociale.

Communauté de destin, avons-nous dit, l'intégration juridique de l'agglomération urbaine du Saguenay repose sur un consensus qui est celui d'appartenir aux mêmes référents identitaires gommant ou neutralisant les aspérités normatives d'un autre âge. Comme si la communication avait non seulement changé la notion de temps, pour signifier que différentes cultures se superposent instantanément et en temps réel, et que l'espace a pris une nouvelle importance également.

Plusieurs pratiquent déjà une culture alternative qui questionne le type actuel de société. Et déjà, plusieurs fuient le type de société où l'on ne peut s'épanouir culturellement de la même façon que certains fuient leur pays devenu trop violent. Dans le monde hypermoderne, non seulement les hommes et les biens circulent-ils, mais la pensée circule également. L'interchangeabilité s'inscrit au niveau de la représentation du monde et, avec la circulation de la pensée, circule aussi l'action sur la pensée. En temps réel, il y $\mathrm{a}$, en quelque sorte, immédiateté à la fois d'une pensée et d'une action sur soi à travers les regards croisés des autres. Au moment où l'image de l'autre arrive à profusion projetée sur les écrans de la vie quotidienne par les communications de masse, apparaît une extension de la place publique et de ses conséquences critiques selon les différentes échelles spatiales des pratiques démocratiques qui, ainsi, introduisent des questionnements sur les repères identitaires de tout un chacun

À titre d'illustration de ce qu'est l'extension de la place publique, la musique produite par les jeunes n'est pas un phénomène isolé, mais un révélateur culturel. Les jeunes mentionnent, par exemple, pratiquer la musique techno à résonances hindo arabique, le hiphop en langue amérindienne, le punk asiatique, etc.; ces genres musicaux constituent autant d'occasions de rencontres et la diversité des formes et des expressions musicales constitue autant de variétés et de sensibilités culturelles. La musique de style anglosaxon existe toujours, mais les jeunes notamment pointent du doigt l'existence réelle d'une culture plurielle dont la musique demeure un élément symbolique de rassemblement, tout en libérant les imaginaires au cœur de la création. Cette variété musicale est présente et bien vivante au Saguenay. Une communion 
de différentes cultures est peut-être un signe d'une mondialisation, d'une mise en relation de la planète au même titre qu'il y a globalisation des intérêts économico-politiques, un intérêt culturel pour ce qui relit aux autres et ce qui se transmet. L'image n'est pas nouvelle, c'est dans la ville que les cultures se rencontrent. On n'a qu'à se rappeler l'émerveillement de Voltaire confronté aux diverses cultures de la ville, ou encore Goerg Simmel qui montrait la ville comme le centre de multiples stimulations nerveuses.

\section{La société de communication et l'économie quaternaire comme imaginaire collectif}

Déjà en 1970, 50 \% de la population active américaine occupait un emploi dans le domaine des communications et en Europe, on estime à $60 \%$ le nombre d'emplois émanant de l'univers des communications ${ }^{8}$. Il ne s'agit pas seulement de l'ensemble de l'industrie des communications de masse, mais de tous les circuits et les réseaux de traitement et de gestion des communications qui, démocratisés, sont au point d'être le support à nos échanges quotidiens. Anne-Marie Gingras signale l'importance stratégique et l'enjeu politique de la réappropriation démocratique des réseaux de communication et l'accès égal à l'électronique pour la maîtrise d'une citoyenneté active $^{9}$. Mais quel type de société et quelle vie urbaine sont en train de se dessiner au moment où se transforment les rapports d'échanges? Qu'est-ce que communiquer? Est-ce plus que la transmission d'informations ? Serait-ce créer une présence autre au moment où l'autre est en présence, comme le démontrent les recherches en cybernétique ? Est-ce participer à définir l'autre, et, par conséquent, inventer une situation toujours incertaine, imprévisible?

Que disent les jeunes confrontés de manière délibérée ou inconsciente à la réalité communicationnelle qu'on peut nommer société de communication et d'information? Que disent donc ces jeunes qui, de manière méthodique, décident de migrer vers les grands centres urbains? Les jeunes qui se retrouvent en une autre ville ne disent-ils pas ainsi l'importance du cadre urbain dans la réalité communicationnelle et l'économie du savoir? La présence à l'autre est une présence de l'autre et une mise en présence avec la différence des autres non pas un mur et une discrimination, pour le moins une inégalité économique et sociale. Dans ce sens, la ville offre un espace déter- minant d'expériences et de découvertes. La culture est ce qui se gagne sur la violence, car la violence est la destruction des frontières et l'absence de cadre. La culture est une conquête et les rites de manifestation culturelle construisent des nouveaux cadres. Les nouveaux rites constitués pacifient les antagonismes et rendent visible ce qui ne peut se dire ni s'expliquer sans se vivre dans un temps et un espace réel. La culture s'érige aux lieux mêmes des forces d'opposition en intégrant plutôt qu'en rejetant. La culture permet la présence de l'autre et réconcilie avec la nature contradictoire de la société. Elle devient un matériau qui permet de sculpter des formes nouvelles et de créer à nouveau. Le cadre urbain est l'expression des émotions et l'édification de formes culturelles qui, à leur tour, libère par la re-création et la ré-invention de la ville. Roger Sue ${ }^{10}$ représente, selon le schéma ci-dessous, l'importance des compétences-connaissances et des services relationnels et mutuels dans l'économie nouvelle qu'il nomme l'« économie quaternaire » par rapport au travail et à la marchandise de l'économie industrielle en train de tomber en obsolescence au Saguenay.

\section{Figure 1 - De l'économie industrielle à l'économie du savoir}

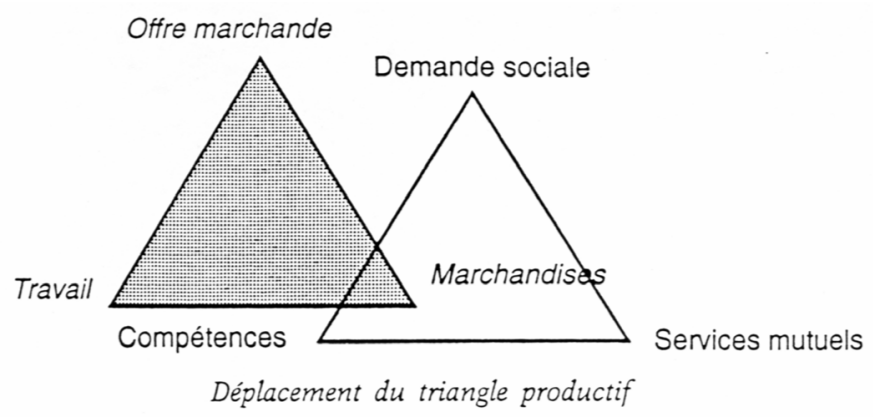

\section{La société de la télécommunication et l'implication politique dans la ville}

La culture et la société communicationnelle commandent-elle une urbanité nouvelle ? Si la société industrielle a façonné une urbanité pour répondre aux exigences de circulation entre les lieux de production et ceux de l'habitation et du commerce, ne faut-il pas repenser la vie urbaine en fonction d'exigences de l'économie en mutation? De l'économie de marché et de la redistribution des biens, ne sommes-nous pas rendus à une économie d'échanges "immatériels » 
réciproques fondés sur une définition de la vie associative pour qui la participation active des élus locaux est différente, à l'image de ce que Jürgen Habermas ${ }^{11}$ nomme la «discussion », comme une réconciliation entre la technique et la démocratie ? La ville devientelle l'espace d'expression d'un lien entre l'économie et le politique, le théâtre d'une démocratie économique plutôt que sa contrainte? Les organisations ne sont plus strictement des entreprises, mais des entités économiques mobiles, labiles voire éphémères mais multiples et variées. Elles ne peuvent plus réclamer d'une façon homogène ou corporative comme les grandes sociétés multinationales. L'intervention politique est totalement différente, proactive, démocratisée.

Manuel Castells écrit :

Tout d'abord, fondamentalement, les technologies ne sont pas la cause, mais des accélérateurs, des amplificateurs des transformations de la structure sociale en politique. D'autre part, face aux nouvelles technologies, des contre-tendances ne cessent de s'affirmer visant à préserver l'identité culturelle, l'expression territoriale des cultures ethniques et communautaires. [...] Mais la gestion de cette contradiction est précisément l'objet de la politique municipale; c'est bien elle qui peut redonner un sens nouveau au mode de développement de nos villes. ${ }^{12}$

Si la ville prend une signification nouvelle dans le contexte de la globalisation, celle-ci ne se limite plus à désigner une différence dans les modes de vie en comparaison avec celui de la campagne. Le milieu rural, on le sait, ne vit plus en référence à des mœurs villageoises tournées sur un noyau communautaire, autarcique et rupestre, pittoresque ou folklorique.

Si l'on s'est habitué à vivre une triple identité politico-juridique en référence à la triple échelle municipale, provinciale et fédérale, ne faut-il pas relier la refondation de la métapole à la reconnaissance tacite d'une autre échelle de pouvoir dont l'existence se matérialise au niveau des organisations supra étatiques telles les Nations Unies, une citoyenneté-monde dans une «ville-monde »? Si, en d'autres mots, l'« économie-monde» (Immanuel Wallerstein) qu'on constate au fil du quotidien dans les achats d'utilité domestique, dans la globalisation de l'économie et les communications ne commanderait-elle pas une « politique-monde ${ }^{13}$ que les gens voient bien émergée ? Dans cette optique, l'organisation territoriale façonnée depuis la Révolution tranquille selon une approche administrative du territoire national découpé en régions ne correspondrait plus symboliquement donc concrètement à la réalité nouvelle. Le résultat crève les yeux, les régions disent l'ampleur du malaise actuel et à défaut, s'épuisent (mettre un puits à sec) littéralement pour ressembler à des « Bagdad Café » nordiques.

Le cadre urbain-rural (métapole) qui captive maintenant les imaginaires collectifs et qui interpelle les différentes pratiques citoyennes actuelles ne peut plus mettre à l'écart la dynamique de la mondialisation. Les populations travaillent en communication constante avec l'ensemble du monde; cependant, leurs réseaux demeurent encore captifs des convergences où les fils-flux-réseaux sont structurés en direction unilatérale vers Québec, Montréal et Toronto, Ottawa. Durant ce temps, les rapports qu'entretiennent les populations en butte à la globalisation des marchés et à la mondialisation des échanges sociales et culturelles sont en porte-à-faux avec ceux dans lequel fonctionnent les décideurs politiques et leurs administrateurs. L'analyse de la globalisation des échanges ne peut pas seulement se présenter comme une simple variable indépendante. Si la population ne peut plus se dérober face aux effets locaux des structures juridiques supra nationales (fermeture des usines traditionnelles vétustes, mouvements migratoires qui affectent les jeunes cohortes, formation mal qualifiante pour les nouveaux besoins de main-d'œuvre, etc.), elle ne peut pas ne pas réagir sans poser la question du rôle et de la place des décideurs politiques situés au plus près de la seule gouvernance accessible aux décisions stratégiques qu'ils contrôlent, à savoir la réorganisation de leurs gouvernements municipaux, ceux qui sont plongés aux racines de ce qui rend possibles les redéploiements d'une nouvelle économie. Si Montréal, Toronto et Vancouver, notamment, connaissent un redéploiement sur le plan de l'économie informationnelle en réseaux, on peut envisager que l'ensemble du pays est en train de refondre les réseaux d'échanges, et les structures de même que les pratiques urbaines sont en transformation, et cette transformation passe par une redéfinition spatiale des multiples échelles de référence identitaire. 


\section{Conclusion}

Les nouvelles ressources ne proviennent plus du sol ou du sous-sol, et les fermetures d'usines de pâtes et papiers de même que celle de la fabrication de l'aluminium sont, à cet égard, assez significatives. Les usines de transformation des matières premières s'orientent vers l'informatisation des processus, ce qui n'est pas sans effets constants sur l'amenuisement de la part du travail manuel au profit des opérations informatisées, réduisant irréversiblement la demande de main-d'œuvre. Or, il ne s'agit pas d'un changement dans la demande de main-d'œuvre, il s'agit d'un changement qualitatif du genre de production et de la conception non seulement du travail mais de la forme $\mathrm{du}$ travail et des liens sociaux de travail. Une forme du travail qui modifie non seulement le rapport entre le lieu de fixation des habitats et l'unité de production, les trajets entre la «maison » et l'« usine » ou le "bureau », mais il faut penser un type qualitativement nouveau de travail qui questionne les rapports entre les composantes de l'unité familiale, les unités de logement où se trouve le travail lui-même et l'activité de production et les activités de reproduction. Ce qui change, par conséquent, ce sont les usages et les pressions, ou ce qu'on réclame de l'ancien quartier dit résidentiel (dortoir) mais aujourd'hui devenu une sphère complexe de travail de production.

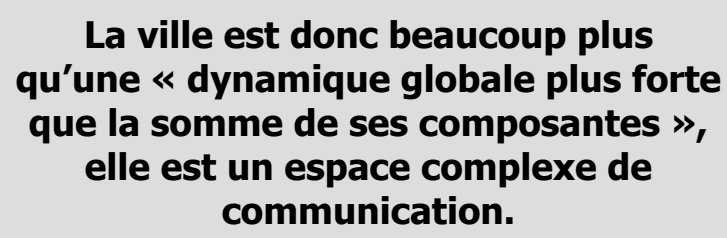

La ville est donc beaucoup plus qu'une «dynamique globale plus forte que la somme de ses composantes », elle est un espace complexe de communication. Prévus pour la seule fonction de reproduction de la force de travail, les zones résidentielles réservées pour la petite famille nucléaire et façonnées pour la socialisation des très jeunes enfants sont des zones qui, loin d'être des milieux propices à la diversité, font fuir les jeunes dès qu'ils atteignent l'âge de l'adolescence. D'autre part, ces quartiers résistent aux transformations de leur cadre. L'adjonction de services, comme le témoignent les constructions pour personnes âgées, les équipements de loisirs pour les jeunes adultes, l'intégration des pratiques culturelles différentes et les activités économiques articulées autour des services à la personne et aux entreprises, sans oublier la frange considérable de professionnels qui trouvent dans les outils informatiques les raisons d'affaires pour s'installer à la maison devenue leur lieu de travail, bref toutes activités reliées à l'émergence de la société des communications trouvent dans ces quartiers un terrain hostile. Les comptables ou les assureurs, en l'occurrence, qui ont transformé leur résidence familiale en bureau, en savent quelque chose, et ceux-ci ne sont plus les seuls; qu'on songe seulement aux différentes types d'hébergement ou de garderie en milieu dit familial, etc. Le quartier résidentiel n'est plus unifonctionnel, il est devenu un site de production et d'échanges multiples.

Il s'agit d'une dynamique sociale et culturelle qui commande, en l'occurrence, une redéfinition de l'environnement urbain, une «économie-territoire » fondée sur la dynamique des " groupes sociaux » ${ }^{14}$ qui rassemblent 1) le monde du travail issu de la société industrielle, 2) le monde de la création artistique et de la recherche scientifique, 3) le monde politique et ce, en direction des foyers ou des milieux de vie comme terreaux actifs de production de connaissances et de compétences. Pour que se concrétisent ces foyers de rencontres, cela nécessite l'invention de moyens de communications et d'informations stratégiques qui, à leur tour, redessinent les supports spatiaux et, de manière inédite, l'organisation culturelle de la ville. Une conception de la proximité axée sur l'interconnexité des liens sociaux suppose un rapprochement de la vie communautaire des citoyens et nécessite obligatoirement l'aménagement de supports routiers et d'équipements collectifs et privés. Dans cette optique, on peut poser que ces foyers composés de groupes en interactions dynamiques et créatrices doivent se détacher du cordon politico-administratif que constitue l'État-nation, et de leurs avatars que sont les multiples composantes administratives régionales, pour repositionner la ville au centre d'une politique imputable et stratégiquement ouverte sur l'ensemble du territoire, bref responsable d'un redéploiement des activités de l'économie globale.

L'hypothèse formulée est que la ville contemporaine s'accommode de la concurrence interne des groupes et des organisations locales, mais l'interdépendance de ses trois grands pôles (demandes sociales/compétences/services mutuels) suscite une dynamique de la communication. À l'idée de la circulation et des 
échanges facilitant la pénétration constante d'innovations et de créations en provenance de partout sur la planète doit correspondre une effervescence culturelle qui émane des populations enracinées d'une manière dynamique sur des territoires particuliers et fondées sur une interdépendance dont les limites ne se contentent plus d'une représentation qui oppose le résidents identifiés selon l'activité industrielle et, désormais, les autres. Il faut tenter de définir ce qu'il est entendu par les relations de proximité et par la notion que Michel Maffesoli nomme l'« enracinement dynamique » et de «mouvements sociaux identitaires» qui redéfinissent un rapport nouveau à l'environnement, mouvements sociaux créateurs de ce que Gilles Verpraet nomme la « citoyenneté active ${ }^{15}$.

\section{Figure 2 - Dynamique de l'interconnexité et la polycentralité au Saguenay}

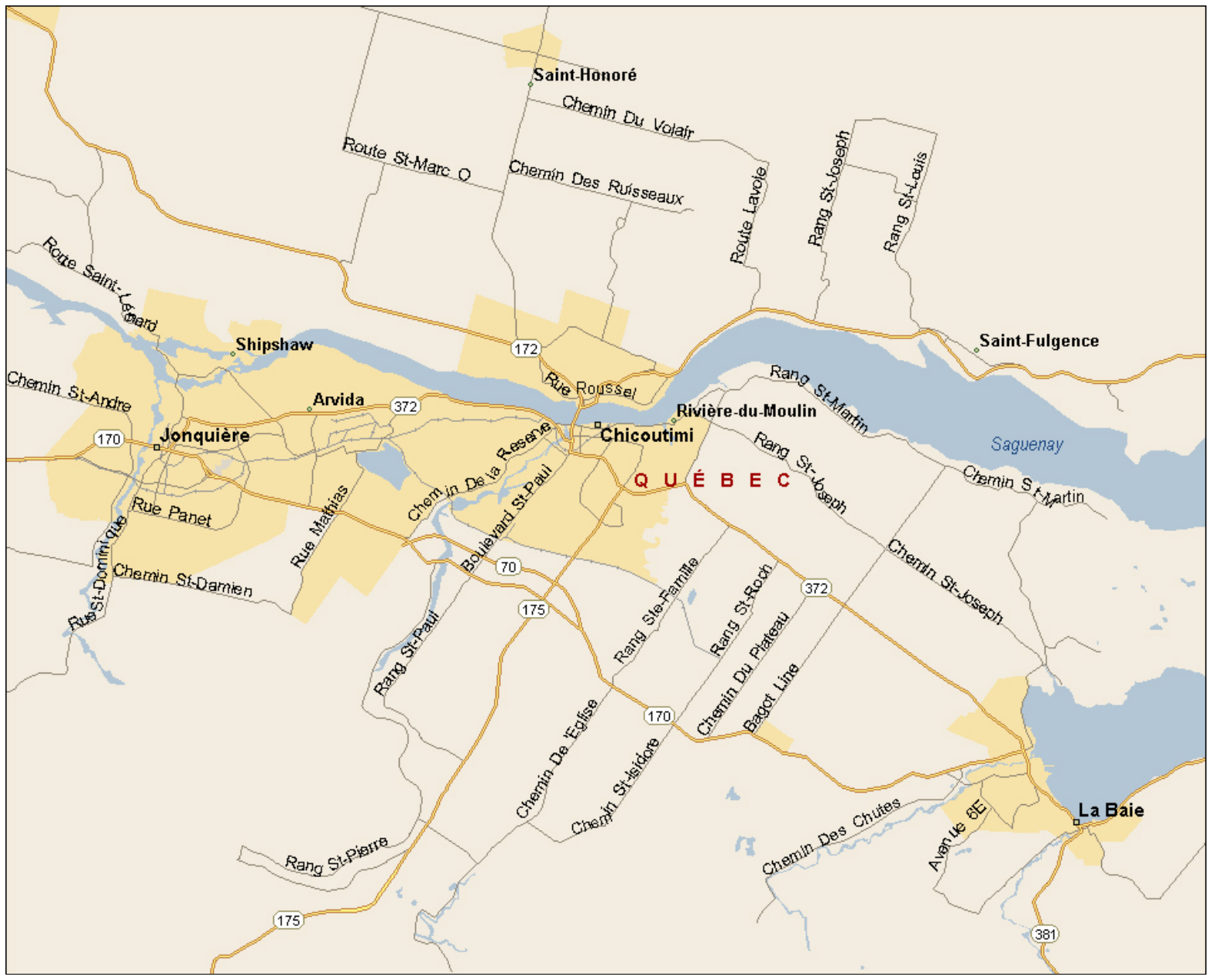

La communication est possible à partir de plusieurs « états d'esprit» particuliers, qui reconstituent l'hétérogénéité mais cette fois, sur une autre base que celle de la concurrence économique fondée arbitrairement à partir des découpages politico-administratifs et des compétitions inter-juridictionnelles. Dans la globalisation des marchés et la mondialisation des communications, les métapoles rassemblent les dynamiques culturelles pour façonner le bouillonnement organisationnel propice à l'éclosion des échanges, et le con- cept de ville-monde prend place partout et y compris dans les anciennes régions dites éloignées par l'autoconstruction d'un sentiment d'appartenance collectif à une «communauté de destin» mais, dans le même temps, se réfléchit dans l'assurance d'une complexité et dans la reconnaissance de différences internes permettant la circulation et la réalisation des multiples facettes de la personnalité de tout un chacun. Philippe Breton et Serge Proulx écrivent : 
Il ne s'agit pas d'adhérer ici à un déterminisme technologique qui conclurait à l'émergence de nouveaux réseaux globaux de solidarité sociale du simple fait de l'existence de réseaux techniques de transmission à l'échelle planétaire. L'émergence d'une conscience citoyenne suppose au contraire une nécessaire distanciation vis-à-vis des illusions de l'idéologie du progrès. [...] [Mais, soulignentils cependant] les nouveaux systèmes de communication médiatisés par l'informatique et les réseaux numériques planétaires donnent naissance à des formes inédites (relativement indépendantes des contraintes d'espace et de temps) de communication et d'échange entre les personnes qui peuvent déboucher sur des formes nouvelles de réseaux sociaux. ${ }^{16}$

Par quoi passe la mise en place d'une diversité et les formes nouvelles de réseaux sociaux? Par l'ouverture et le risque inhérent à l'ouverture aux autres. Par la dépense créatrice d'un réseau de communication qui n'exclut certainement pas la construction de routes et la modernisation des voies ferrées adaptées à l'âge de la mobilité. Au lieu de ressentir comme une pathologie la mobilité qu'exprime la «migration» des jeunes, notamment, il faut assurer une mobilité bien organisée entre toutes les composantes du vaste territoire canadien et, par conséquent, faciliter les échanges non seulement économiques qui sont essentiels, mais aussi des transactions sociales qui assurent la perduration et l'expression de la vie sociale qu'est la culture. Si le fonds anthropologique commun garantit contre l'épreuve de la transformation économique en cours, ce fonds patrimonial s'actualise autour de paramètres sociaux diversifiés importants. La diversité culturelle locale s'exprime par une composition sociale particulièrement variée. L'essor industriel des « Trente glorieuses » a pu voir naître non seulement un espace stratifié selon l'ordre hiérarchique modelé par l'organisation du travail entre les classes ouvrières et les classes dirigeantes qui, ensuite et quasi en rappel des oppositions ayant cours sur le milieu du travail, se distribuaient sur le territoire en quartiers favorisés et quartiers relativement défavorisés. La valeur foncière et le prix des maisons sur le marché immobilier permettent d'évaluer ces différences sociales. Différences sociales issues de l'histoire économique, mais aussi différences territoriales s'observent comme expressions de l'hétérogénéité sociale.
Il y a donc, trop brièvement esquissé, le charme et tout le pittoresque de la diversité et de l'hétérogénéité sociale qui fonde la spécificité culturelle du Saguenay. C'est cette spécificité culturelle qu'il ne faut pas tétaniser dans une réduction moniste de type archéologique, voire comme artefact fossilisé en attraits pour l'exploitation touristique stricto sensu. Il faut considérer ce fonds anthropologique comme un potentiel, un « capital culturel » comme l'a bien souvent défini le sociologue Pierre Bourdieu, notamment. La culture comme expression d'une solidarité en acte qui se réfléchit dans la créativité est une réponse volontaire et, par conséquent, consciente du risque. De quel risque s'agit-il ? Celui que déjà R.E. Park identifiait de manière sibylline, à savoir que : «l'obstacle ultime à la communication, c'est la conscience de soi $\gg{ }^{17}$.

\section{Notes et références}

1 Park, R.E. (1925). « The Natural History of the Newspaper », The City, p. 108, dans Y. Grafmeyer et I. Joseph (1979), L'école de Chicago. Naissance de l'écologie urbaine, p. 39.

2 Le terme de métapole est utilisé dans le sens conceptuel défini par Pierre Lassave dans son ouvrage Sciences sociales et littérature, Paris, PUF, 2002, p. 88 notamment. Essentiellement, il s'agit d'un terme d'urbanisme qui désigne l'hégémonie du cadre spatio-temporel de la ville sur le monde qui y habite. Conceptuellement, il désigne une articulation des banlieues intégrées à l'intérieur d'une même agglomération qui fait alterner les espaces habités et les espaces inhabités, voire les anciens espaces de desserte et les terrains vagues ou en friche. Ici, le concept signale le moment transitoire du passage de la métropolisation du territoire régional en une urbanisation plurielle qui correspond aux différents centres d'activités et aux différents milieux de vie des citadins. Il ne s'agit plus de penser la convergence en direction d'une métropole dite régionale que l'auteur réserve pour la période industrielle de production et consommation de masse. Il ne s'agit plus de considérer un centre unique où convergent les actions économiques, politiques et symboliques culturellement (Centre des affaires, place publique et symbolique unique, etc.), aussi varié soit-il. Mais, il s'agit de penser une pluralité de centres attractifs et une polycentralité différemment utilisée selon les goûts et les besoins de tous les citadins. Il n'y a plus, ainsi conceptualisé, un ou deux pôles attractifs en concurrence parce que similaire et à l'image de l'autre, mais une variété de pôles diversifiés et une pluralité de situations qui, chacune à leur façon, procèdent à l'édification et à la matérialisation de la complexité économique, sociale et culturelle. En un mot, le concept inclut le rural et l'urbain dans une tension dynamique proactive et polycentrée. 
3 Rocher, Guy (1968). Introduction à la sociologie générale, Tome 1. L'action sociale, Éd. HMH/Points, \#13, p. 117.

4 harvey.com, consultant (novembre 2002). « Avant-projet de politique culturelle de la Ville de Saguenay », en vue de la consultation publique du 7 décembre 2002, 45 p.

5 Dumont, Fernand (1968). Le lieu de l'homme. La culture comme distance et mémoire, Montréal, Éditions Hurtubise/ $\mathrm{HMH}$, p. 53.

6 Dressler, Wanda (2004). «Villes mondiales : refondation mégapolitaine, restructuration sociale et transformations identitaires », dans P.-W. Boudreault et M. Parazelli (dir.), $L$ 'imaginaire urbain et les jeunes. La ville comme espace identitaire et créatrice, Sainte-Foy, PUQ.

7 Maffesoli, Michel (1993). La contemplation du monde, Paris, Grasset, coll. « Livre de poche », p. 49.

8 De Coster, Michel, Bernadette Bawin-Legros et Marc Poncelet (2001). Introduction à la sociologie, Bruxelles, Éd. De Boeck-Université, p. 191.

9 Gingras, Anne-Marie (1999), Médias et démocratie. Le grand malentendu, Québec, PUQ, p. 219.

10 Sue, Roger (1997). La richesse des hommes. Vers l'économie quaternaire, Paris, Éditions Odile Jacob, p. 143.
11 Habermas, Jürgen (1978). La technique et la science comme idéologie. La fin de la métaphysique, Denoël/Gonthier, coll. Médiations, \#167, p. XLIV.

12 Castells, Manuel (1988). «Innovation technologique et centralité urbaine ", dans Cahiers de recherche sociologique, sous le thème: La reconquête de la ville, vol. 6 , $\mathrm{n}^{\mathrm{o}} 2$, p. $35-36$.

13 Vieille, Paul (1986). «Du transnational au politiquemonde ? », dans Peuples méditerranéens, \# 35-36, Fin du national ? Paris, p. 309-338.

14 Boudreault, Pierre (1986). Luttes régionnalitaires et société postindustrielle, Jonquière, Éd. Sagamie/Québec.

15 Verpraet, Gilles (2003). «Les nouveaux arguments de la citoyenneté active », dans P.-W. Boudreault (dir.), Retours de l'utopie. Recompositions des espaces et mutations du politique, Québec, Presses de l'Université Laval, p. 91103.

16 Breton, Philippe et Serge Proulx (2002). L'Explosion de la communication à l'aube du XXI siècle, Montréal, Boréal/ La Découverte, p. 307.

17 Park, R.E., op. cit., p. 22. 


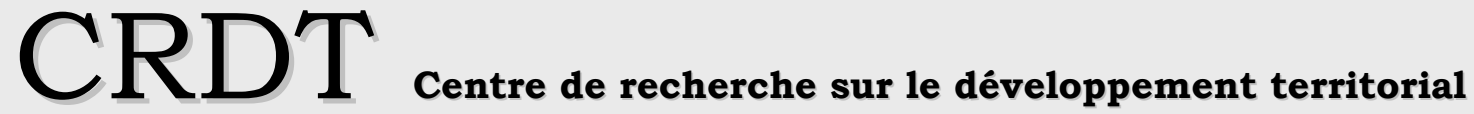

Le Centre de recherche sur le développement territorial (CRDT) est un regroupement stratégique de chercheurs actifs depuis longtemps dans plusieurs universités du réseau de I'Université du Québec. Avec le soutien du FQRSC (Fond québécois de recherche sur la société et la culture), ce nouveau centre de recherche met en synergie des chercheurs de I'Université du Québec à Rimouski (UQAR), à Chicoutimi (UQAC), en Abitibi-Témiscamingue (UQAT) et en Outaouais (UQO). Il regroupe aussi plusieurs chercheurs associées ou collaborateurs canadiens, américains et européens.

Le CRDT met en œuvre un programme intégré de recherche comparative sur la question du développement territorial, dans une perspective de développement durable. Ce programme porte sur les processus et les dynamiques territorialement ancrés de développement; il identifie et rend intelligibles leurs impacts pour les collectivités territoriales. Le CRDT concerte les efforts de production, de partage et de valorisation des connaissances sur le développement territorial. Les travaux de recherche permettront de suivre, de comparer et d'évaluer des expérimentations en cours, de diagnostiquer les forces et les faiblesses des territoires, de dégager les enseignements de ces expériences de développement local et régional et de réinvestir ces nouveaux savoirs dans la formation et le soutien aux initiatives de développement territorial.

Au Québec, comme ailleurs dans le monde, des voies de développement et d'aménagement durables du territoire sont recherchées afin d'assurer la satisfaction des besoins et l'épanouissement des populations, tout en poursuivant des objectifs d'équité sociale, de ménagement de la nature, d'innovation économique et sociale et de participation démocratique. Dans cette perspective, la prise en compte de tous les territoires, de leur diversité et de leurs traits distinctifs, de leurs atouts, et de leur complémentarité devient une impérieuse nécessité.

La direction scientifique du CRDT est assurée par Bruno Jean de I'UQAR, titulaire de la Chaire de recherche du Canada en développement rural, assisté de deux codirecteurs, Marc-Urbain Proulx de I'UQAC et Danielle Lafontaine de I'UQAR, ainsi que de trois directeurs d'axes thématiques de recherche: Guy Chiasson de I'UQO, Christiane Gagnon de I'UQAC et Serge Côté de I'UQAR. Trois codirecteurs d'axes complètent l'équipe de direction : Patrice Leblanc de I'UQAT, Serge Gagnon de I'UQO et Fernand Harvey de I'INRS Urbanisation, Société et Culture. 